\title{
Sequence and structural requirements for optimal guide RNA-directed insertional editing within Leishmania tarentolae
}

\author{
RAJ D. PAI, ${ }^{1,2}$ LISA M. OPPEGARD, ${ }^{1}$ and GREGORY J. CONNELL \\ Department of Pharmacology, Medical School, University of Minnesota, Minneapolis, Minnesota 55455, USA
}

\begin{abstract}
The coding sequence of several mitochondrial mRNAs of the trypanosomatid family of protozoa is created by the guide RNA-directed insertion and deletion of uridylates (Us). Selection-amplification was used to explore the sequence and structure of the guide RNA and mRNA required for efficient insertional editing within a mitochondrial extract prepared from Leishmania tarentolae. This study identifies several novel features of the editing reaction in addition to several that are consistent with the previous mutagenesis and phylogenetic analysis of the reaction in Trypanosoma brucei, a distantly related trypanosomatid. Specifically, there is a strong bias against cytidines $5^{\prime}$ of the editing sites and guanosines immediately $3^{\prime}$ of guiding nucleotides. $U$ insertions are directed both $5^{\prime}$ and $3^{\prime}$ of a genomically encoded $U$, which was previously assumed not to occur. Base pairing immediately flanking an editing site can significantly stimulate the editing reaction and affect the reaction fidelity but is not essential. Likewise, single-stranded RNA in the region upstream of the editing site, not necessarily immediately adjacent, can facilitate editing but is also not essential. The editing of an RNA containing many of the optimal features is linear with increasing quantities of extract permitting specific activity measurements to be made that are not possible with previously described $T$. brucei and $L$. tarentolae assays. The reaction catalyzed by the $L$. tarentolae extract can be highly accurate, which does not support a proposed model for editing that was based largely on the inaccuracy of an earlier in vitro reaction.
\end{abstract}

Keywords: RNA editing; trypanosome; uridylate; selection-amplification; SELEX

\section{INTRODUCTION}

One of the most intriguing forms of RNA processing reactions is the uridylate $(\mathrm{U})$ insertion and deletion editing required to produce a functional open reading frame in several mitochondrial mRNAs of the trypanosomatid protozoa (Benne et al. 1986; for reviews, see Estevez and Simpson 1999; Madison-Antenucci et al. 2002; Stuart and Panigrahi 2002). Part of the genetic information determining the location of the editing is carried on guide RNAs (gRNAs). A specific gRNA is able to bind to its cognate mRNA immediately $3^{\prime}$ of a block of editing sites and also contains a guide complementary to a block of edited se-

\footnotetext{
${ }^{1}$ These authors contributed equally to this work.

Reprint requests to: Gregory J. Connell, Department of Pharmacology, Medical School, University of Minnesota, 6-120 Jackson Hall, 321 Church Street SE, Minneapolis, MN 55455, USA; e-mail: gconnell@lenti.med.umn. edu.

Present address: ${ }^{2}$ Department of Molecular and Cellular Biology, University of California at Berkeley, Berkeley, CA 94720, USA

Article and publication are at http://www.rnajournal.org/cgi/doi/ 10.1261/rna.2175703.
}

quence (Blum et al. 1990). It has been demonstrated in vitro that the appropriate gRNA directs the $\mathrm{U}$ insertions and deletions at the editing sites; changing the guiding sequence of the gRNA results in the corresponding change to the number of $U$ insertions and deletions (Byrne et al. 1996; Cruz-Reyes and Sollner-Webb 1996; Kable at al. 1996; Seiwert et al. 1996).

Editing has been proposed to proceed through a reaction that is initiated at an editing site by an endonucleolytic cleavage producing a $5^{\prime}$ fragment with a $3^{\prime}$ hydroxyl and a $3^{\prime}$ fragment with a $5^{\prime}$ monophosphate (Blum et al. 1990). U-addition or -deletion activities acting at the $3^{\prime}$ hydroxyl followed by religation of the $5^{\prime}$ and $3^{\prime}$ fragments would complete one editing cycle. Experimental evidence in support of the proposed mechanism has been obtained in vitro (Byrne et al. 1996; Cruz-Reyes and Sollner-Webb 1996; Kable at al. 1996; Seiwert et al. 1996; Igo et al. 2000).

The machinery catalyzing in vitro gRNA-directed insertional and deletional editing is part of a large complex that sediments at 20S on a glycerol gradient (Pollard et al. 1992; Corell et al. 1996). Only a few proteins have so far been 
unambiguously demonstrated to be essential for editing (for reviews, see Madison-Antenucci et al. 2002; Stuart and Panigrahi 2002). Two RNA ligases have been independently identified in Trypanosoma brucei by several groups: a $48-\mathrm{kD}$ mature protein designated as TbMP52 (Schnaufer et al. 2001), band IV (Rusche et al. 2001), or p52 (McManus et al. 2001) and a $45-\mathrm{kD}$ mature protein designated as TbMP48 (Schnaufer et al. 2001), band V (Rusche et al. 2001), or p48 (McManus et al. 2001). TbMP52 has been unambiguously demonstrated to be essential for editing (Schnaufer et al. 2001). Although TbMP48 is also associated with the editing complex, it is not essential for the reaction (Drozdz et al. 2002). Band III (Huang et al. 2002) /TbMP 63 (Panigrahi et al. 2001b) and TbMP81 (Drozdz et al. 2002) are essential for editing and have been suggested to be required for proper endonuclease function, but their precise roles have not yet been defined. A terminal uridyltttransferase (TUTase) activity has recently been purified from Leishmania tarentolae (Aphasizhev et al. 2002), but it has not been demonstrated that it is the activity that catalyzes $U$ additions during the editing reaction, and its role in editing is unclear, as it does not appear to cofractionate with the editing complex (Panigrahi et al. 2001b).

In addition to gRNA-directed $U$ insertions, in vitro $U$ insertions have also been demonstrated to occur independent of gRNA (Connell et al. 1997; Brown et al. 1999). The activity cofractionates with the gRNA-directed activity (Oppegard and Connell 2002; Oppegard et al. 2000) and was shown to be dependent upon an $\mathrm{A}+\mathrm{U}$ element that is present within the $5^{\prime}$ untranslated sequence of the mRNA encoding cytochrome $b$ (Brown et al. 1999). The U insertions are induced within the sequence both $5^{\prime}$ and $3^{\prime}$ of the element. Highly similar A $+\mathrm{U}$ sequences are also present within a cytochrome $b$ gRNA and within the $5^{\prime}$ untranslated sequence of the ND7 mRNA (Brown et al. 1999). The A + U sequence is sufficient to induce in vitro $U$ insertions when placed into a normally nonedited transcript, but unlike gRNAs, the $\mathrm{A}+\mathrm{U}$ element is unable to stimulate editing when added in trans. Although the biological significance of the $\mathrm{A}+\mathrm{U}$ element still is not clear, cytochrome $b$ mRNA isolated from $L$. tarentolae mitochondria is also modified at sites immediately flanking the $\mathrm{A}+\mathrm{U}$ element, suggesting that a similar reaction may occur in vivo (Oppegard et al. 2000).

The sites modified by the editing machinery would have to be highly controlled in order to prevent potential lethal alterations of the mitochondrial RNA. Mutagenesis (CruzReyes et al. 2001; Kabb et al. 2001; Igo et al. 2002) and phylogenetic analysis (Burgess and Stuart 2000) have previously been used to identify critical structures of the gRNA and mRNA that define an editing site. We exploited selection-amplification (Ellington and Szostak 1990; Tuerk and Gold 1990), which has the advantage of being able to explore significantly more sequence space than mutagenesis, to further characterize the RNA sequence and structure de- fining an editing site. Several novel features of the editing reaction were identified in addition to several that are consistent with the previous mutagenesis and phylogeny studies.

\section{RESULTS}

\section{Selection of optimal editing substrates}

Selection-amplification (Ellington and Szostak 1990; Tuerk and Gold 1990) was initially used to explore the sequence and structural requirements necessary to support insertional editing within a mitochondrial extract prepared from L. tarentolae. A 70-nt RNA containing 23 random positions (Fig. 1A, nt 28-50) was incubated with editing extract and UTP as described in the Materials and Methods. The small fraction of RNAs within the random population that is able to act as a substrate for the editing reaction was partitioned from the larger unedited fraction by gel electrophoresis. A region of the gel consistent with the size expected if there were one to three $U$ insertions was excised. The eluted RNA was reverse transcribed, amplified by PCR and T7 transcription and gel purified for subsequent enrichment. T4 RNA ligase was used to circularize the RNA prior to using it as an editing substrate so as to block the activity of a TUTase that is present within the editing extract.

The selection-amplification was designed to obtain RNA sequences that support the insertion of Us within the fixed sequences flanking the random region (Fig. 1A). The PCR primers and low stringency PCR amplification conditions used were chosen so as to regenerate these sites for subsequent cycles of enrichment; RNAs containing $U$ insertions within the fixed sequence were used to optimize the amplification conditions prior to starting the selection (not shown). Insertions at sites within the random region itself would be selected against by this strategy because these editing sites could not be regenerated for subsequent editing and reselection. Slower migrating RNA, consistent with that expected from edited product, was visible after the fourth cycle of selection (Fig. 1B). Because there was no significant further increase in the fraction of slower migrating product after a subsequent cycle of enrichment (not shown), the fourth-cycle RNA pool was cloned for sequence analysis.

There were at least five possible outcomes from the selection. First, RNAs could have been selected that had additional nucleotides added during the reverse transcription, PCR, or T7 transcription reactions. This population of RNAs was selected against, however, by a stringent size selection of the RNA pool by gel electrophoresis prior to the editing reaction. Second, a binding site for a gRNA present within the editing extract could have been selected. Although gRNAs could be present within the enriched editing extract used for the selection reactions, it is unlikely that there would be sufficient quantity to significantly drive the reaction. In addition, the majority of the gRNAs present 
A

\section{(1) (10) (20) (27) 51 \\ 60 (N) GCGUUUAACUUGUUCUUGUU \\ GGUUGCUUUAUUUGUGGGAUAAAUUUA(N) GCGUUUAAC}

1. circularize to block $3^{\prime} \mathrm{U}$ addition activity

2. treatment with editing extract

3. separation of products

on a $9 \%$ polyacrylamide gel

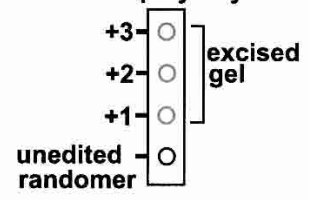

4. amplification and editing site regeneration

A. RT-PCR

\begin{abstract}
forward primer: T7 promoter GGTTGCTTTATTTGTGGGATAAATTTA reverse (cDNA)primer: AACAAGAACAAGTTAAACGC
\end{abstract}

\section{B. $T 7$ transcription}

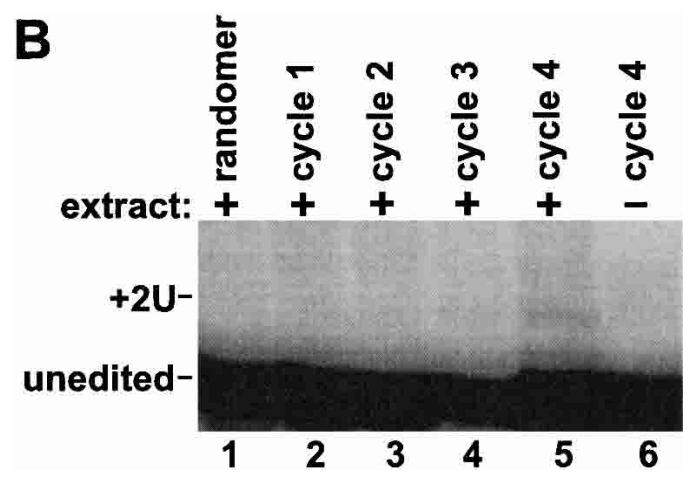

FIGURE 1. Selection-amplification of RNAs supporting the insertion of Us within an in vitro editing extract. (A) A schematic illustrating one cycle of the selection-amplification strategy. A 70-nt RNA containing a 23-nt random region was circularized to block a $3^{\prime} \mathrm{U}$ addition activity that is present within the editing extract. After treating the circular RNA with the editing extract, slower mobility RNAs were resolved from unedited RNA by gel electrophoresis. The RNA eluted from the excised part of the gel was amplified for T7 RNA polymerase mediated transcription by RT-PCR using the indicated primers. $(B)$ The starting random RNA and the RNA from the first four cycles of selection were treated with the $L$. tarentolae editing extract. Slower migrating RNA, consistent with edited product, was visible after the fourth cycle of selection.

within the L. tarentolae strain used in this study have been identified (Maslov and Simpson 1992; Thiemann et al. 1994), and, as a result, it would have been possible to identify this class of RNAs if they had been selected. Third, a sequence that supports the gRNA-independent reaction could have been selected. Several classes of RNA motifs that have gRNA-independent characteristics were, in fact, identified, and these will be described elsewhere. Fourth, transacting gRNAs could have been selected. For a trans-acting gRNA-like molecule to be selected, it would also have to be edited, and the likelihood of two RNAs pairing together with the ability to guide the editing of each other is highly improbable especially during the initial cycles of selection. Fifth, a sequence could be selected that is able to function as a cis-acting gRNA. Cis-acting gRNAs have been demonstrated to direct in vitro editing reactions (Kapushoc and Simpson 1999) and a cis-acting gRNA has also been hypothesized to direct the editing of the COII pre-mRNA in vivo (Blum et al. 1990). This study is focused solely on a group of selected RNAs that fall into the latter category and provide novel insight into the sequence and structural requirements for gRNA-directed editing.

\section{A selected cis-acting gRNA}

Thirty clones from the fourth-round selection were sequenced. Six of the selected clones contain the indicated consensus sequence within the 23-nt initially random part of the RNA (Fig. 2A, nt 28-50). All six members of the consensus group and five of the six tested RNAs selected without the consensus were found to be substrates for the editing reaction (not shown), which is consistent with the selection having reached a plateau by cycle 4. All six members of the consensus group had two $\mathrm{U}$ insertions added by the extract between nt 19 and 21 (Fig. 2B); because nt 20 is a $\mathrm{U}$, there was ambiguity in the precise localization of the insertions. All six members could be folded into two similar structures that placed two A or G nucleotides, potentially guiding nucleotides, directly opposite the site immediately $5^{\prime}$ (conformation A) or 3' (conformation B) of U-20 (Fig. 2B).

RNA A-1, a representative RNA, was probed with the chemical modifying agents dimethyl sulfate (DMS) and 1-cyclohexyl-3-(2-morpholinoethyl)carbodi-

imide metho- $p$-toluene sulfonate (CMCT) to obtain support for the predicted structures (Fig. 2B). Whereas DMS modifies $\mathrm{C}$ and $\mathrm{A}$ nucleotides at Watson-Crick positions that are not involved in secondary or tertiary interactions, CMCT will modify the nonprotected Watson-Crick positions of $\mathrm{G}$ and $\mathrm{U}$ nucleotides; modifications were detected by RT primer extension. The intensity of the RT product of the RNA treated with DMS and CMCT was corrected for the modification-independent termination, and the ratio of the corrected intensity obtained under native conditions to that obtained under denaturing conditions was calculated for each position. Mean ratios were calculated from four 
A group A consensus: (AA)RTTTAARTCCY clone \#

A-1: ATGTTAAGTTTAAATCCTCCGCG

A-2: TGTGAAGTTTAAATCCCCCAGCG

A-3: GTTGAAATAAGTTTAAGTCCCGG

A-4: CAAAAGTTTAAGTCCCGGAGGCG

A-5: ACGTCAAATTTAAATCCCGGTTG

A-6: TCGTTTAAATCCCATCATTTGTG

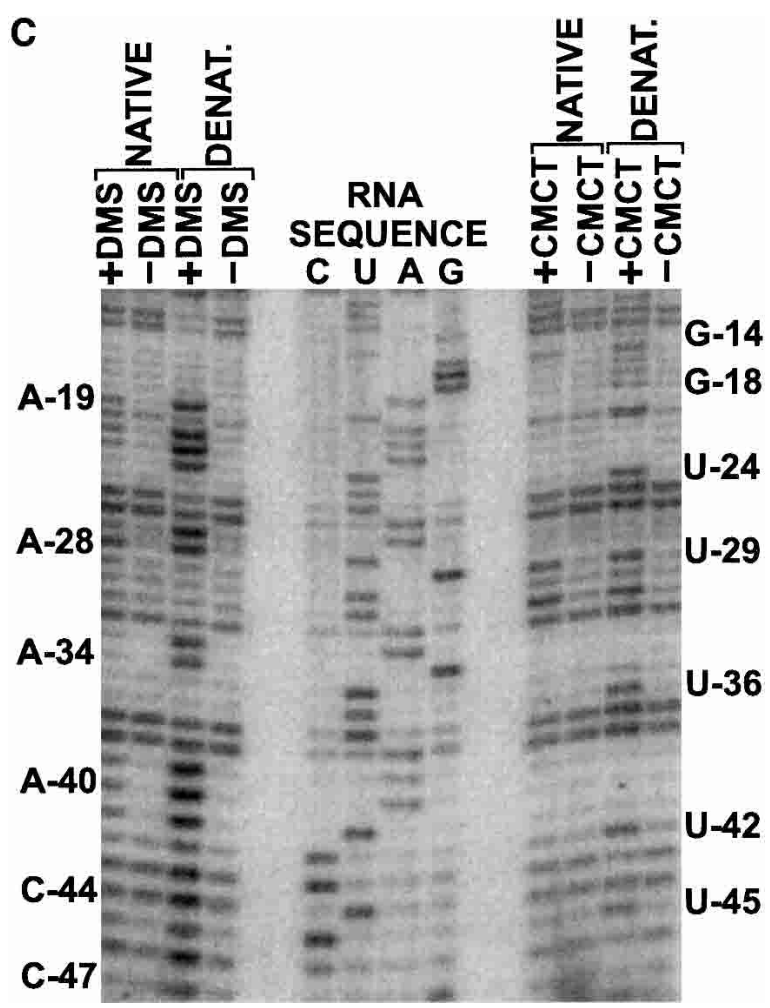

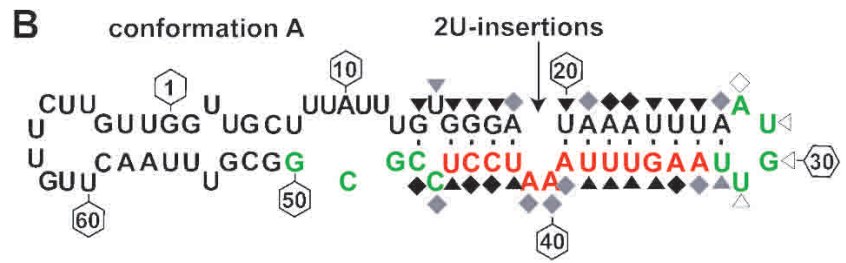

conformation B

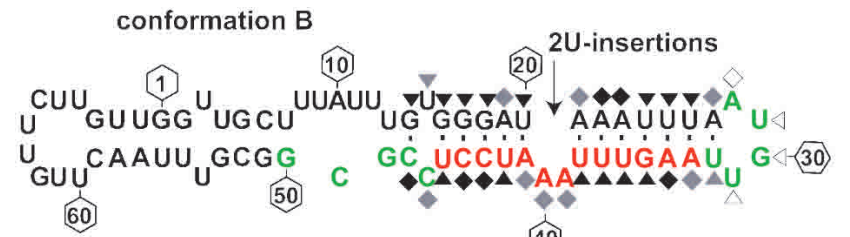

[40)

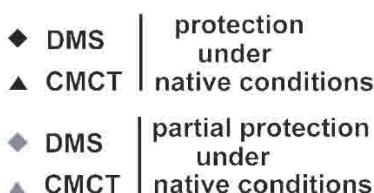

DMS $\quad \begin{gathered}\text { under } \\ \text { undiotion }\end{gathered}$ CMCT $I$ native conditions

AMCT native conditions

FIGURE 2. Six of the selected RNAs have a highly similar sequence and can form secondary structures suggesting that the selected sequence functions as a cis-acting gRNA. (A) The RNA from the fourth cycle of selection was amplified by RT-PCR for cloning and sequencing. Six of the selected clones contain the indicated consensus sequence (red). Clone A-6 does not have the two 5' As (parentheses) present on the other five clones. Selected sequence that is not part of the consensus is in green. (B) All six members of the consensus group have two Us inserted by the editing extract between A-19 and A-21 and can be folded into two alternative conformations in which two potential guiding nucleotides are placed either $5^{\prime}$ (conformation A) or $3^{\prime}$ (conformation B) of U-20. The sequence of the RNA that remained fixed during the selection is in black. A representative RNA, RNA A-1, was probed with DMS and CMCT under both native and denaturing conditions. The ratio of the intensity of the RT extension product obtained under native to that obtained under denaturing conditions was calculated at each indicated position. Mean ratios were calculated from four independent sets of DMS and three independent sets of CMCT reactions. A base is defined as protected if the native:denaturing ratio is $<0.2$, partially protected if the ratio is $\geq 0.2$ and $<0.5$ and unprotected if the ratio is $\geq 0.5$. (C) A representative gel.

independent sets of DMS and three independent sets of CMCT reactions. A base was defined as protected if the native:denaturing ratio is $<0.2$, partially protected if the ratio is $\geq 0.2$ and $<0.5$ and unprotected if the ratio is $\geq 0.5$ (Fig. 2B). Overall, the chemical modification results are consistent with the predicted secondary structure of the A-1 RNA (Fig. 2B,C). For example, the predicted loop nt A-28 to U-31 are very reactive under native conditions, whereas those nucleotides within a predicted helix are mostly protected from modification. The chemical modification data, however, does not give any insight as to which of the two possible conformations is favored in the absence of the editing complex as A-39, A-40, and A-41 are all partially protected to a similar extent.

To determine whether nt A-39-A-41 are acting as guiding nucleotides, as predicted from the secondary structure (Fig. 2B), mutagenesis of this region was performed. The selected 70-nt A-1 RNA is predicted to have two guiding nucleotides. Consistent with this possibility, 2 nt are inserted into the RNA by the extract (Fig. 3A, 72-nt band of lane 1); sequencing confirmed that two $U$ insertions occur between nt 19 and 21 (data not shown). A minor 69-nt 


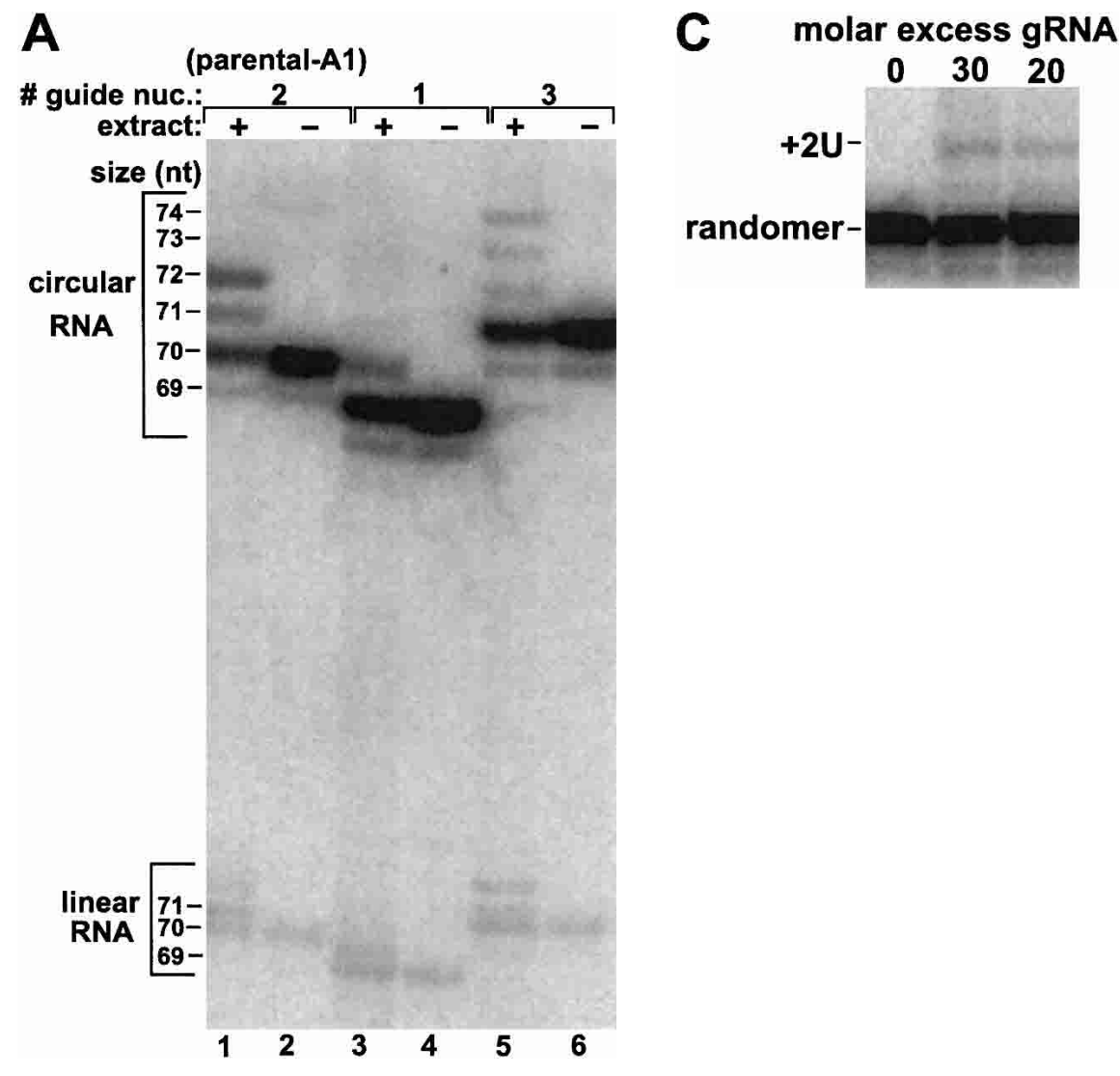

B

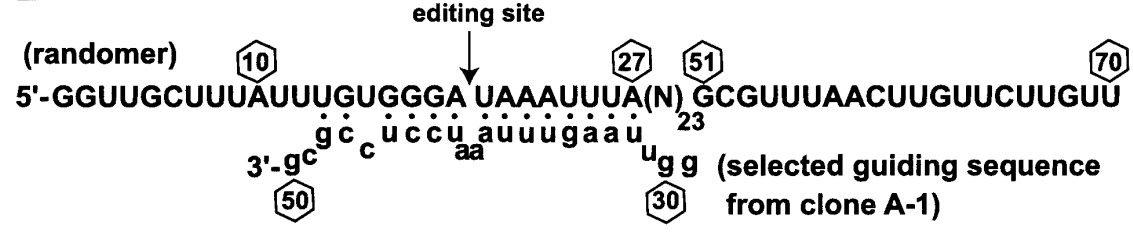

FIGURE 3. The selected sequence functions as a gRNA. (A) Changing the number of predicted guiding nucleotides resulted in a corresponding change in the number of Us inserted between A-19 and A-21. (B) Predicted pairing of the selected guiding sequence from clone A-1 with the starting randomer RNA used for the in vitro selection. The guiding sequence has an additional $5^{\prime} \mathrm{G}$ to facilitate its in vitro transcription (Milligan and Uhlenbeck 1989). (C) The selected A-1 sequence can function as a trans-acting gRNA. A molar excess of an RNA containing nt G-30G-50 of the selected A-1 sequence, including two guiding nucleotides, is able to direct correct editing of the starting random RNA population.

band present in the non-extract-treated RNA (lane 2) probably results from ligation of contaminating N-1 RNA during the circularization reaction, and correct editing of this RNA may account for a portion of the 71-nt edited product (lane 1). Deletion of one of the predicted guiding A nucleotides resulted in the insertion of one fewer Us into the RNA (lanes 3,4$)$. Likewise, the addition of a third potential guiding nucleotide (A-42) resulted in three $\mathrm{U}$ insertions (lanes $5,6)$. The guiding is significantly more precise than any other previously described gRNA-directed reaction that is catalyzed by mitochondrial extracts (Oppegard et al. 2000; Kabb et al. 2001; Oppegard and Connell 2002) or lysates
(Byrne et al. 1996; Kapushoc and Simpson 1999) prepared from L. tarentolae. Linear molecules, some of which are consistent with the size expected of editing reaction intermediates, are formed during the reaction, although other unrelated processes could also be producing these products.

It was next determined whether the selected cis-acting gRNA sequence could also act in trans, like the majority of natural gRNAs. The random RNA pool used for the initial cycle of selection, as already indicated, does not significantly become edited within the extract (Fig. 1B, lane 1). The selected guiding sequence from clone A-1 (Fig. $2 \mathrm{~B}$, nt 30-50) would be expected to bind to the fixed sequence of the randomer (nt 13-27) and guide $\mathrm{U}$ insertions between sites 19 and 21 if it is able to act in trans (Fig. 3B). A 20-30fold molar excess of the gRNA sequence from clone A- 1 should be able to compensate for much of the entropic advantage associated with having the gRNA sequence in cis. The addition of a 20- or 30-fold molar excess of an RNA containing only the selected gRNA sequence from clone A-1 is, in fact, sufficient to rescue accurate editing of the random RNA pool within the extract (Fig. 3C). This is unlike an $\mathrm{A}+\mathrm{U}$ sequence element required for the gRNA-independent reaction that is unable to function in trans (Oppegard et al. 2000). Even though the selected guiding part of the A-1 sequence can act in trans, it is unlikely that the parental A-1 RNA is forming intermolecular duplexes, with one selected region serving as a gRNA for the opposing molecule, rather than the intramolecular duplex depicted in Figure 2B. As well as the editing reaction being less efficient when the selected guiding sequence is added in trans even at a 30 -fold molar excess, no evidence of intermolecular duplexes are evident from native gel analysis of the A-1 RNA (not shown).

\section{Editing occurs both $5^{\prime}$ and $3^{\prime}$ of a $U$ that is immediately adjacent to an editing site}

A TLC-based assay was used to determine whether the in vitro $U$ insertions occur at the site $5^{\prime}$ or $3^{\prime}$ of U-20 (Fig. 4A). Unlabeled A-1 RNA was modified for the assay so that 

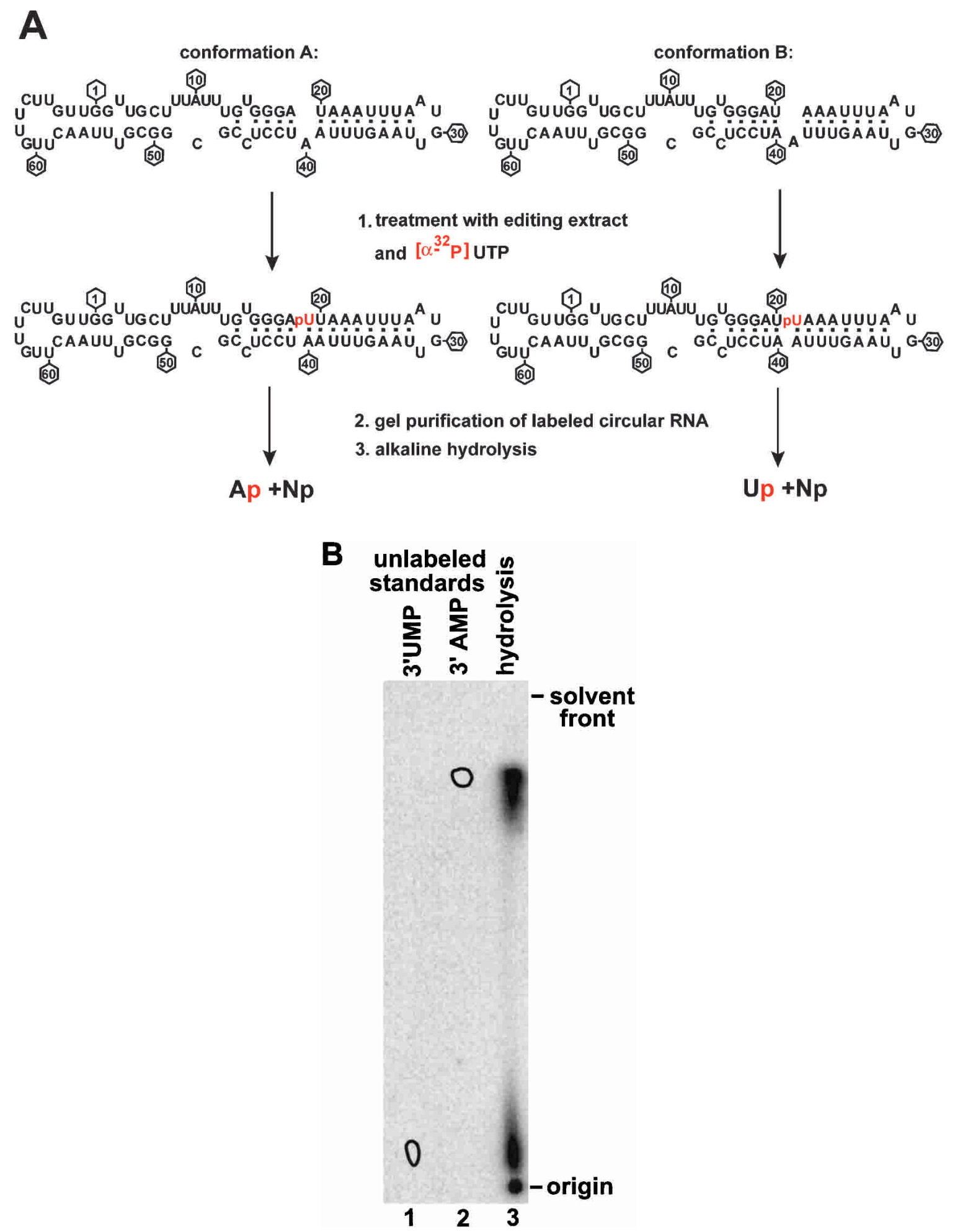

FIGURE 4. U insertions occur both $5^{\prime}$ and $3^{\prime}$ of a genomically encoded $U$. (A) The selected RNA can potentially form two different conformations in which guiding nucleotides direct insertions either 5' (conformation A) or 3' (conformation B) of U-20. A TLC-based assay was used to distinguish between the two possibilities. Unlabeled circular A-1 RNA with one guiding nucleotide was treated with editing extract in the presence of $\left[\alpha-{ }^{32} \mathrm{P}\right]$-UTP. Whereas the labeled phosphate will be inserted immediately $3^{\prime}$ of A-19 by editing of conformation A, it will be inserted immediately $3^{\prime}$ of U-20 by editing of conformation B. Complete alkaline hydrolysis of the gel-purified extract-treated circular RNA will produce a labeled $2^{\prime}-3^{\prime}$ cyclic A or U monophosphate depending on whether the editing occurred $5^{\prime}$ or $3^{\prime}$ of U-20. (B) Analysis of the hydrolysis products on poly(ethylenimine) cellulose TLC plates resolved in $1 \mathrm{M}$ formic acid indicates that U insertions occur equally both $5^{\prime}$ and $3^{\prime}$ of $\mathrm{U}_{-} 20$. Unlabeled 3' AMP and 3' UMP standards were used as markers and were visualized under UV light. The TLC plate is representative of three independent experiments. 
it contained only one guiding nucleotide (Fig. 3A, lanes $3,4)$. Treatment of this RNA with $\left[\alpha{ }^{32} \mathrm{P}\right]$-UTP in the presence of editing extract would result in the labeled phosphate being put $3^{\prime}$ of an $A$ if the $U$ is inserted $5^{\prime}$ of $\mathrm{U}-20$ (conformation A) or $3^{\prime}$ of a $\mathrm{U}$ if it is inserted $5^{\prime}$ of A-21 (conformation B). Complete alkaline hydrolysis would result in the formation of a ${ }^{32} \mathrm{P}$-labeled $2^{\prime}-3^{\prime}$ cyclic nucleotide monophosphate that is subsequently converted into a mixture of $2^{\prime}$ and $3^{\prime}$ monophosphates upon neutralization with acid.

After gel purifying the extract-treated A-1 RNA, it was hydrolyzed at $98^{\circ} \mathrm{C}$ in $50 \mathrm{mM} \mathrm{NaOH}$. The hydrolysis products were resolved on a poly(ethylenimine) cellulose TLC plate in $1 \mathrm{M}$ formic acid. At this $\mathrm{pH}$, adenine but not uracil is positively charged, and, as a result, the adenosine monophosphates are readily resolved from the uridine monophosphates (Fig. 4B, lanes 1,2; Zweig and Sherma 1972). The RNA hydrolysis products, labeled in the extract and comigrating with the A and $\mathrm{U}$ monophosphate standards, have equal intensity, indicating that Us are being guided into the sites both $5^{\prime}$ and $3^{\prime}$ of U-20. It was previously assumed that Us are only inserted $5^{\prime}$ of a genomically encoded U (Burgess and Stuart 2000). Although the insertion site ambiguity is of mechanistic interest, it does not appear to cause misediting (Fig. 3A) and the open reading frame created by the editing of natural mRNAs would be unaffected by the ambiguity.

\section{Base pairing upstream of the editing sites contributes to efficient editing}

The selection results unambiguously indicate that base pairing immediately upstream of the editing site contributes to the editing reaction. The double-stranded region immediately upstream of the editing sites of RNA A-1 (Fig. 2B) that is formed by the pairing of (G-16, G-17, G-18, A-19) with (U-45, C-44, C-43, U-42) is conserved in all other members of the selected consensus group (Fig. 2A). The upstream base pairing could have been selected to stabilize the overall secondary structure of the RNA or alternatively the conformation of the RNA immediately upstream of the editing site could be impacting the reaction. To distinguish between these two possibilities, additional mutagenesis was performed. As expected, substitution of nt 42-44 with nucleotides that would disrupt the upstream base pairing (Fig. 5A, minus upper helix) inhibits the editing reaction (Fig. 5B, lanes 3,4 ). However, editing activity is not recovered by increasing the stability of the lower helix through additional base pairs (Fig. 5A, extended lower helix; Fig. 5B, lanes 5,6). The result suggests that the conformation of the nucleotides immediately upstream of the editing sites impact the reaction.

It had previously been reported that in the reaction catalyzed by the T. brucei editing extract, base pairing immediately upstream of the editing site can be inhibitory to in- sertional editing (Igo et al. 2002). The upper helix of RNA A-1 was further stabilized to determine whether an inhibitory effect could also be detected within the L. tarentolae extract (Fig. 5A, extended upper helix). The additional stabilization results in a $40 \%$ decrease in the fraction of edited product (Fig. 5C, lanes 3,4). Additional stabilization of the upper helix (Fig. 5A, minus upper loop) has no further inhibitory effect (lanes 5,6). This mutation also indicates that the internal loop centered around nt 10 (Fig. 2B) does not significantly contribute to the reaction. In addition, extensive mutations to the remaining part of the fixed sequence (nt 1-6 and 51-70) also have no significant effect on editing efficiency (not shown), indicating that they are not relevant to the RNA's ability to act as an editing substrate. This fixed sequence was not deleted from the A-1 RNA for the remaining studies because the ligation reaction used to circularize the RNA, prior to using it as an editing substrate, is inhibited with the smaller RNA (not shown).

\section{Sequence specificity of the nucleotides immediately flanking the editing sites}

The initial selection was intentionally designed so that RNA sequences able to guide $\mathrm{U}$ insertions into the flanking fixed sequence (Fig. 1A, nt 1-27 and 51-70) would be selected; this enabled the editing sites to be regenerated for subsequent cycles of enrichment. As a consequence of part of the selected RNA structure not being random in the original selection, only a limited subset of the possible permutations of this region would have been explored. To more fully explore the sequence requirements immediately flanking the editing sites, these regions were randomized for an additional cycle of selection (Fig. 6A,B). The sequence of the forward PCR primer used in the amplification of the reselected RNA was adjusted so as not to overlap the randomized positions. Only those sequenced clones that had U insertions located within the expected editing site(s), indicating that the corresponding RNAs were substrates for the editing reaction, were used to generate the reselected phylogenies.

Two reselections were performed. The 4 nt comprising the $2 \mathrm{bp}$ immediately downstream of the editing site of conformation A (Fig. 2B) were initially randomized for one cycle of reselection (Fig. 6A). Reselection of a $U$ at position 20 potentially could regenerate conformation $B$ and would complicate the interpretation of the results as the reselected nucleotides could be in two different positions relative to the editing site (Fig. 2B). However, when a $\mathrm{U}$ is not at position 20 , it becomes possible to interpret the results exclusively in terms of conformation A. The $4 \mathrm{nt}$ comprising 2 bp upstream of the editing site were also randomized and the RNA treated with the extract in a separate reselection (Fig. 6B). These $2 \mathrm{bp}$ are immediately adjacent to the editing site indicated in conformation $\mathrm{A}$ but would be $1 \mathrm{bp}$ further upstream of the editing site in conformation B (Fig. 


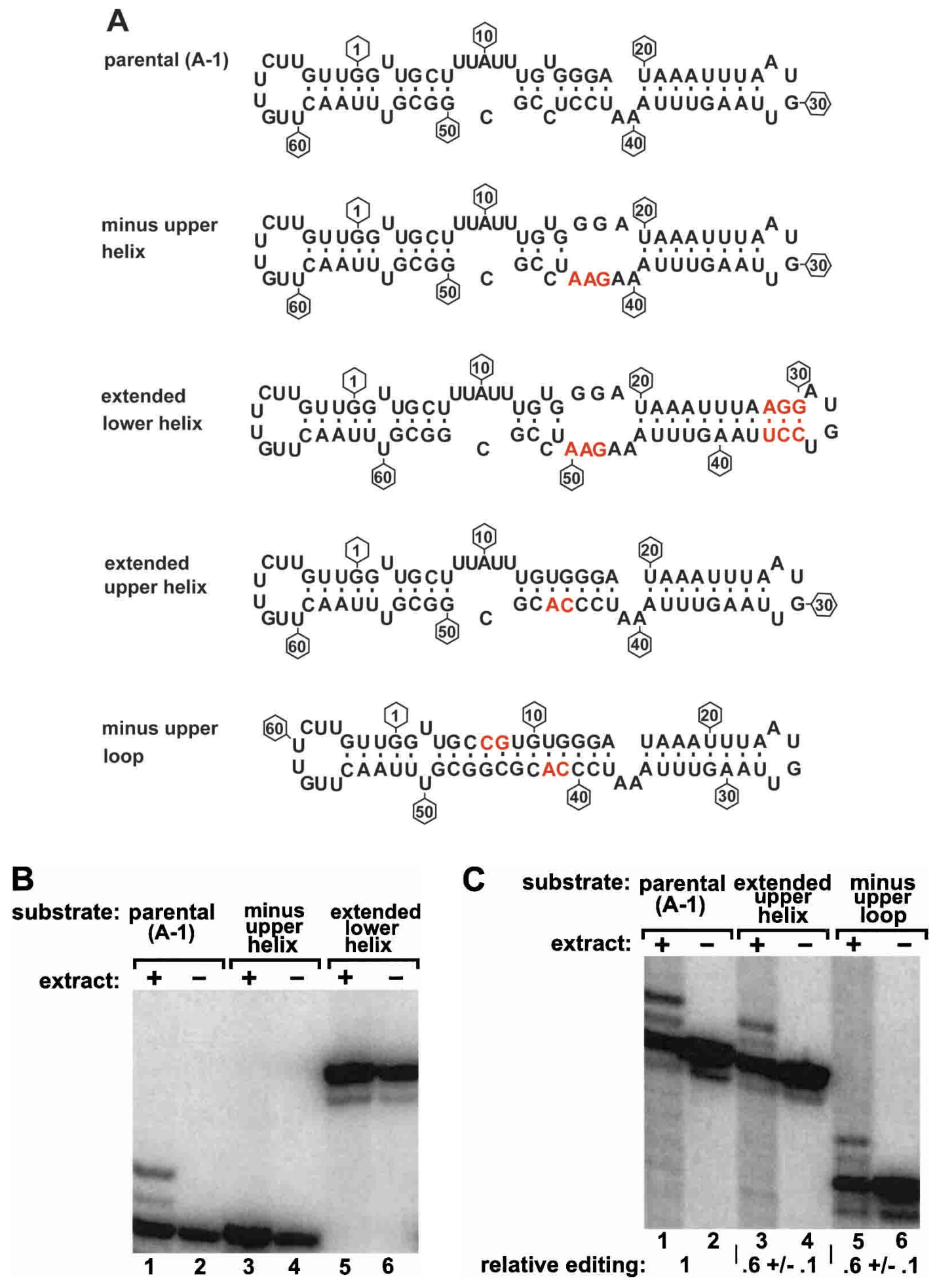

FIGURE 5. A duplex immediately upstream of the editing site affects insertional editing. (A) The location of some of the mutations used to probe the significance of the duplex upstream of the editing sites (red). Only the structure of the parental RNA indicated in Figure 2B is supported by chemical modification studies. $(B)$ Disruption of the duplex immediately upstream of the editing sites cannot be compensated by additional stabilization of the downstream duplex. The gel is representative of two sets of reactions. (C) Additional stabilization of the upstream duplex partially inhibits the editing reaction. For each RNA, the fraction of correctly edited product was normalized to the fraction of correctly edited parental RNA. The mean relative editing values and standard deviations calculated from two sets of reactions are indicated beneath the gel. 
2B). Although the conformational heterogeneity results in ambiguity in the precise location of the upstream base pairs, generalities can still be made regarding the sequence preference of the upstream region.

Inspection of the two generated phylogenies indicated that there are distinct sequence preferences within the region flanking the editing site(s). Notably, there is a strong bias against $\mathrm{Cs}$ upstream of the editing site that is not observed in the downstream reselection (Fig. 6A,B). None of 19 RNAs obtained from the upstream reselection have a C at either position 18 or 19 (Fig. 6B). There is also a strong bias against Gs at positions $3^{\prime}$ of the guiding nucleotides that is not observed immediately $5^{\prime}$ of the guiding nucleotides (Fig. 6A,B). None of the 19 RNAs from the upstream reselection had a $\mathrm{G}$ at position 42 or 43 (Fig. 6B). Although base pairing is preferred both downstream from and upstream of the editing sites, the reselected phylogenies also indicate that particular non-Watson-Crick pairings are tolerated within both regions. However, some mismatched combinations were not detected at any of the reselected positions (Fig. 6A,B). These include C-A, C-C, A-G, G-G and G-A mismatches. This sequence bias may also contribute, in part, to the inhibition observed with the minus upper helix mutation (Fig. 5A,B). Sequencing confirmed that each of the 4 nt was represented at the randomized positions within the starting RNA populations used for both reselections (not shown); this indicates that the sequence preferences did not result from a large bias in the synthesis of the randomers.

Although sequencing of the reselected RNAs indicated that they were edited within the extract, it was likely that some are suboptimal substrates, as only one cycle of reselection was performed. To determine the relative effect of the selected variants on the extent and fidelity of editing, several reselected RNAs were individually treated with the editing extract (Fig. 6C-E). Substitution of the U-20/A-39 base pair with other matched pairs does not improve the fidelity of the reaction, indicating that neither the conformational ambiguity (Fig. 2B) nor an A immediately adjacent to the guiding nucleotides are adversely affecting fidelity (Fig. 6C, lanes 1,2,5-8). As expected, the efficiency of editing is adversely affected by mismatches within the downstream helix (Fig. 6D). Several reselected RNAs with mismatches within this duplex reduced editing approximately 10 -fold. The fidelity of the reaction can also be adversely affected by mismatches in this region as indicated by the RNA with a U-20/U-39 mismatch (Fig. 6D, lanes 5,6). This RNA is predominantly edited with only one $U$ insertion rather than the two insertions expected from correct editing. It is possible that the mismatch could be directly affecting the fidelity of the editing complex, or, alternatively, it could be causing local conformational changes that alter the number of guiding nucleotides. For example, G-21 could be pairing with U-39 and U-20 with A-40 leaving one guiding nucleotide. Aside from the base-pairing require- ment, the editing reaction is not significantly affected by the downstream sequence.

In contrast, there appear to be additional constraints on the upstream sequence (Fig. 6E). The (A-18, U-19/U-43, A-42) RNA is edited to only $40 \%$ that of the parental RNA, and fidelity is also affected as indicated by an increase in the fraction of incorrectly edited +3 product (lanes $1,2,5,6$ ). Likewise, substitution of the single parental A-19/U-42 pair with a U-19/A-42 pair results in a 30\% decrease in editing and a loss of fidelity (Fig. 6E, lanes 1,2,7,8). Substitution with an A-19/A-42 mismatch results in a further $50 \%$ reduction of edited product, and the correctly edited +2 product is no longer prominent (lanes 9,10). The loss of fidelity is even more pronounced when additional substitutions to the G-18/C-43 pair are made (lanes 11,12); the prominent product contains one $U$ insertion rather than the two expected from correct editing. It is possible that in the reselected (U-18, A-19/C-43, A-42) RNA (lanes 11,12), the formation of U-18/A-42, G-17/C-43, and G-16/C-44 WatsonCrick pairs and an A-19/A-41 mismatch would leave one guiding nucleotide (Fig. 6B).

\section{The fraction of edited RNA increases linearly with the extract concentration}

The in vitro editing of $L$. tarentolae cytochrome $b$ (Oppegard and Connell 2002) and T. brucei ATPase 6 mRNA (Rusche et al. 1997; Panigrahi et al. 2001a) derivatives have previously been used to monitor the fractionation of the editing extract. However, the fraction of the substrate RNAs that become edited does not increase linearly with increasing quantities of added extract, making it difficult to measure changes in specific activity during the fractionation. One possible explanation for the editing efficiency not increasing with increasing amounts of extract would be if a particular conformation of the substrate RNA is required for editing and is limiting the reaction. Because optimal folding would have been one of the influences affecting the in vitro selection, we were interested in determining whether editing of the selected A-1 RNA increased with an increasing quantity of extract. One picomole of radiolabeled A-1 RNA was treated with an increasing quantity of mitochondrial extract and the fraction of correctly edited product relative to total RNA, including correctly edited, unedited, incorrectly edited, and degradation products, was calculated for each condition. The reaction is linear over a range of $3 \%-40 \%$ correctly edited product (Fig. 7) making it a good substrate to monitor the enrichment of the editing complex. The result further suggests that there is an active conformation of the gRNA-mRNA duplex that was limiting in the previously described assays.

\section{DISCUSSION}

Several of the critical RNA features required for efficient editing have previously been defined. There has been phy- 

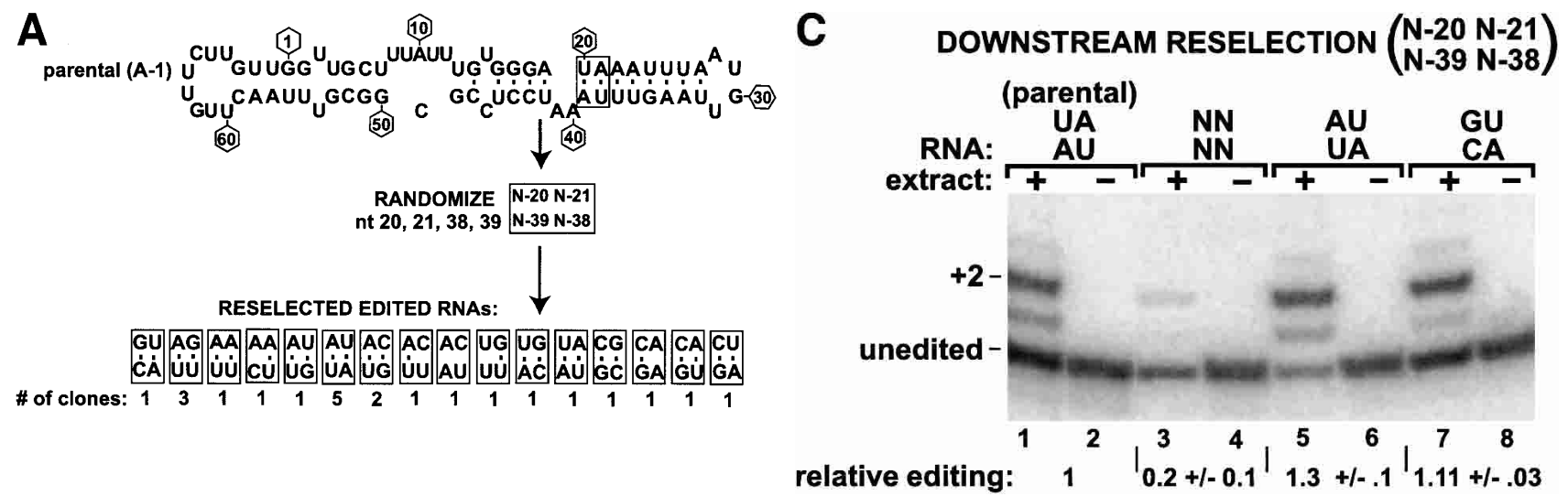

B
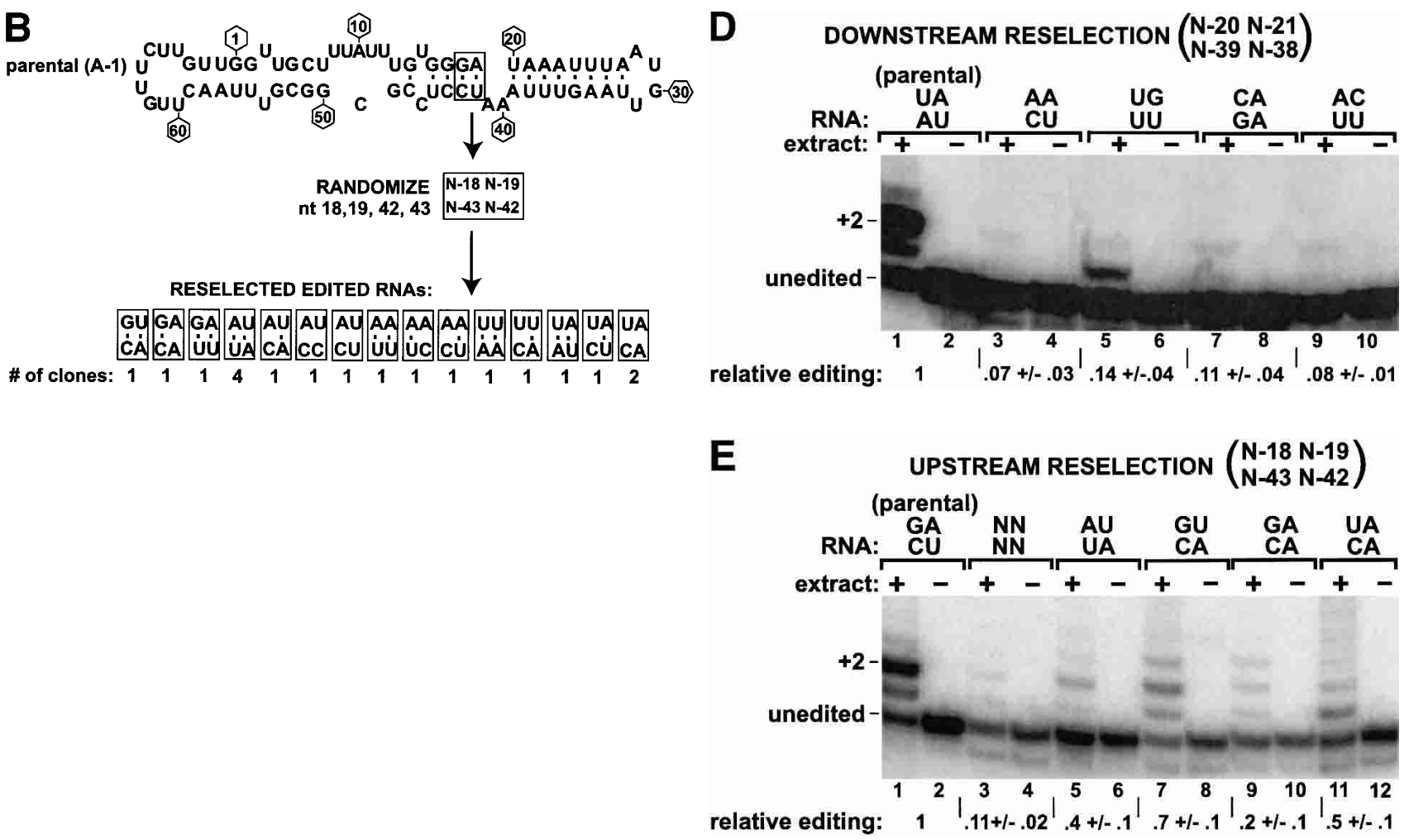

FIGURE 6. Sequence specificity of the nucleotides immediately flanking the editing site. (A) Two base pairs immediately downstream from the editing site were randomized for one cycle of reselection. The sequences of the reselected edited RNAs are indicated. $(B)$ The two indicated base pairs upstream of the editing site were also randomized for an independent reselection. $(C)$ Editing of the parental A-1 RNA (UA/AU), the RNA randomized at the downstream $(A)$ positions $(\mathrm{NN} / \mathrm{NN})$, and two RNAs from the downstream reselection that maintain Watson-Crick pairing within the selected sequence. The gel is representative of three sets of reactions. For each RNA, the fraction of correctly edited product was normalized to the fraction of correctly edited parental RNA. The mean relative editing values and standard deviations calculated from the three data sets are indicated beneath the gel. $(D)$ Editing of the parental A-1 RNA (UA/AU) and four RNAs from the downstream reselection that have mismatches within the selected sequence. The gel is representative of two sets of reactions. (E) Editing of the parental A-1 RNA (GA/CU), the RNA randomized at the upstream $(B)$ positions $(\mathrm{NN} / \mathrm{NN})$, and four RNAs obtained from the upstream reselection. The gel is representative of three sets of reactions.

logenetic analysis of the sequence flanking sites of editing of T. brucei mRNAs (Burgess and Stuart 2000), mutagenesis of an ATPase 6 and cytochrome $b$ mRNA and gRNA-derived transcripts assayed in a $T$. brucei in vitro editing assay (Cruz-Reyes et al. 1998, 2001; Igo et al. 2000, 2002), and mutagenesis of a cytochrome $b$ and ND7 mRNA and
gRNA-derived transcripts assayed in a $L$. tarentolae in vitro editing assay (Kapuschoc and Simpson 1999; Oppegard et al. 2000; Kabb et al. 2001). The selection-amplification described here allowed significantly more sequence space to be explored than was possible with the previous mutagenesis studies. In addition, contrasting the selection-amplification 


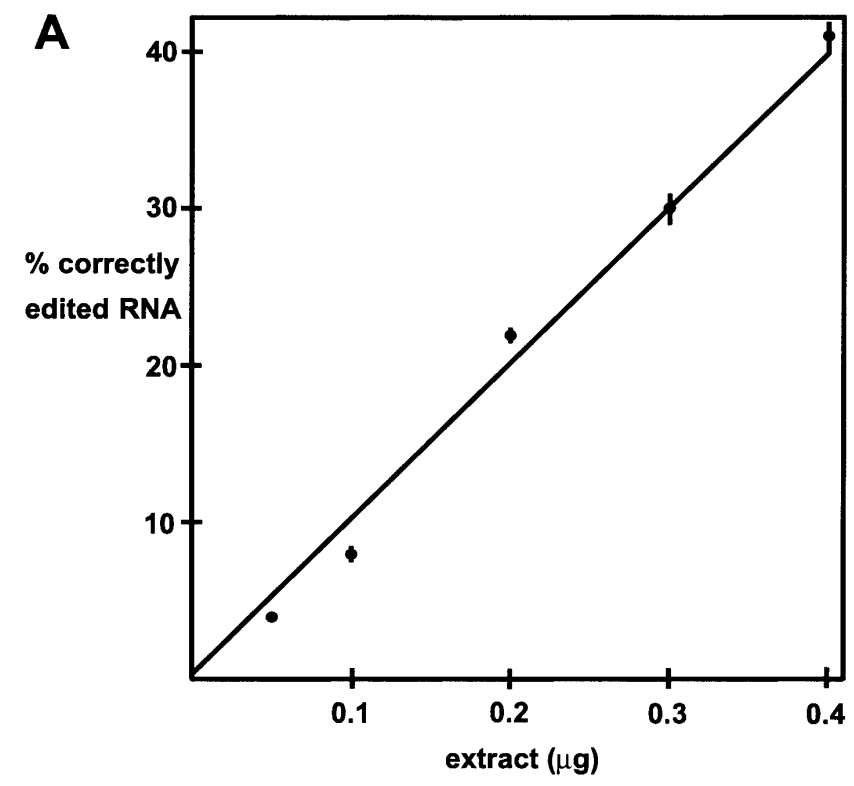

B

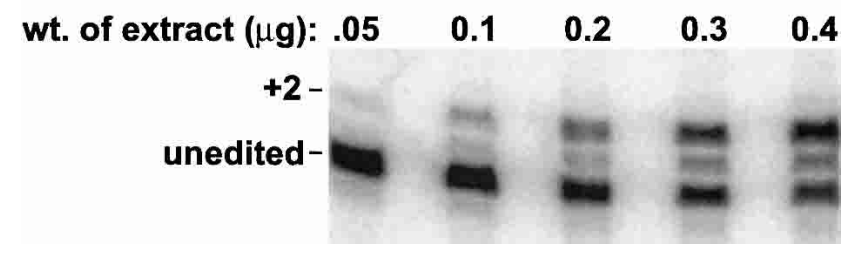

FIGURE 7. RNA editing increases linearly with added extract. (A) One picomole of radiolabeled RNA was incubated with the indicated amount of editing extract. The ratio of correctly edited product to total RNA, including correctly edited, unedited, incorrectly edited, and degradation products, was calculated for each reaction. Each point is the mean of three independent reactions and the standard deviation, where significant, is indicated by a vertical line. (B) A representative set of reactions.

results with the earlier mutagenesis and phylogenic studies is of value in distinguishing those effects that may be unique to a particular RNA, in vitro assay or trypanosomatid species from those that are more general characteristics of the trypanosomatid editing reaction.

\section{Sequence bias in the mRNA sequence flanking the editing sites}

The selection-amplification results clearly indicate that Cs are not tolerated at sites upstream of insertional editing. None of the 19 reselected RNAs had a C at either of the randomized upstream positions (Fig. 6B). This is consistent with the phylogenetic analysis (Burgess and Stuart 2000) and the earlier mutagenesis in both T. brucei (Igo et al. 2002) and L. tarentolae (Kabb et al. 2001), and suggests that it is a general characteristic of trypanosomatid editing.

The phylogenetic analysis at sites of T. brucei insertional editing indicated that there is a strong bias against Us immediately adjacent to editing sites (Burgess and Stuart 2000). Limited mutagenesis also indicated that substitution of an A immediately upstream of an editing site with a $\mathrm{U}$ partially inhibited T. brucei insertional editing, suggesting that a $U$ at this position in some manner interferes with catalysis (Igo et al. 2002). This is consistent with the loss of editing efficiency and fidelity observed with the U-19/A-42 substitutions (Fig. 6E, lanes 5-8). However, our results also indicate that the effect is not a general feature of the trypanosomatid editing reaction. The TLC-based assay of RNA A-1 clearly indicates that Us are inserted equally into the conformation A editing site containing a flanking upstream $A$ and the conformation $B$ site with an upstream flanking $\mathrm{U}$ (Fig. 4). Furthermore, it is also clear that a flanking $U$ in this context does not adversely affect the accuracy of the in vitro reaction; changing the flanking $\mathrm{U}(\mathrm{U}-20)$ to other bases did not improve fidelity (Fig. 6C). As a result, part of the phylogenetic bias against genomically encoded Us could simply be a consequence of the Us being added to the mRNA after transcription through editing.

There was also a strong bias against the reselection of a $G$ at position 19, upstream of the editing site (Fig. 6B). This result is not consistent with the phylogenetic analysis (Burgess and Stuart 2000) nor with previous mutagenesis studies (Kabb et al. 2001; Igo et al. 2002). It is possible that the bias against a $G$ in the reselection results from its potential to disrupt the conformation near the editing sites by pairing with C-43 or C-44 (Fig. 2B). Whatever the cause, the bias against a $\mathrm{G}$ at this location is unique to this particular RNA and not a general characteristic of the reaction.

\section{Important features of the gRNA}

There is a requirement for an anchor sequence that is complementary to the mRNA immediately downstream of the editing sites. This is supported by both the selected phylogeny and chemical protection study and is consistent with earlier mutagenesis (Kable et al. 1996; Seiwert et al. 1996) and the natural phylogeny (Blum et al. 1990; for review, see Benne 1992). The downstream anchor of the A-1 gRNA sequence is 8 bp (Fig. 2B), which is within the range of what is found in nature (for review, see Benne 1992), and having the gRNA in cis would be expected to contribute additional binding energy (Freier et al. 1986). As expected, mutations within the RNA A-1 anchor sequence that disrupt Watson-Crick pairing also reduce editing (Fig. 6D).

The in vitro selected guiding nucleotides are predominantly As, with only two of the selected RNAs (Fig. 2A, A-3 and $\mathrm{A}-4$ ) having a $\mathrm{G}$ at one of the guiding positions. Because each of the six selected group A RNAs contains three guiding nucleotides (Fig. 2B, nt 40 and 41 for conformation A and nt 39 and 40 for conformation B of RNA A-1), there is a 16 out of $18 \mathrm{nt}$ bias for As over Gs at the guiding 
positions. The preference for guiding As over Gs is consistent with the previous mutagenesis (Igo et al. 2002).

The in vitro selection results indicate that there is a strong bias against Gs immediately 3 ' of the guiding nucleotides. None of the 19 reselected RNAs had a G at either position 42 or 43 (Fig. 6B). It has previously been proposed that a $\mathrm{G}$ immediately flanking a guiding nucleotide is selected against at insertional editing sites in nature because the specificity of the number of Us inserted could potentially be adversely effected by the potential of a flanking G, like an A, to act as a guiding nucleotide (Burgess and Stuart 2000). Although misguiding by a flanking purine could be selected against in nature, the constraint does not account for the bias against Gs during the in vitro selection, as accuracy was not a major selection criterion. Furthermore, an A was selected at position 39 , immediately adjacent to the guiding nucleotides that also would have the misguiding potential (Fig. 2B), and it does not appear to adversely affect fidelity, at least in this context (Figs. 3A, 6C). It is also difficult to envision how a $\mathrm{G}$ selected at position 43 (Fig. $6 \mathrm{~B}), 2 \mathrm{nt}$ removed from the $3^{\prime}$-most guiding nucleotide of conformation $\mathrm{A}$ and $3 \mathrm{nt}$ from that of conformation B, could adversely affect guiding. This strong bias $2 \mathrm{nt}$ removed from the $3^{\prime}$-most guiding nucleotide, however, is not consistent with the natural phylogeny and is therefore not a general property of the trypanosome reaction. Part, but not all, of the bias could be explained by the bias against Cs at positions 18 and 19, which would be required to pair with these positions for optimal editing. However, base pairing with Gs at positions 42 and 43 could still have been preserved when Us were selected at positions 18 and 19. In fact, when a $U$ was selected at positions 18 or 19 , every nucleotide except $\mathrm{G}$ was selected opposite it at positions 42 or 43 (Fig. 6B).

Conversely, the bias against Cs at positions 18 and 19 cannot fully be explained by a bias against Gs at positions 42 and 43 , as there was also the potential for the selection of nonpaired Cs. C-U mismatches were obtained in the downstream reselection (Fig. 6A) and other mismatches were obtained in the upstream reselection (Fig. 6B), suggesting that the bias against an unpaired $\mathrm{C}$ in the upstream helix is not completely related to its effect on helix stability. Although the molecular rationale is not yet completely understood, Gs 3' of the guiding nucleotides, like Cs 5' of the editing site, inhibit the editing reaction.

The in vitro selection results indicate that base pairing upstream of the editing sites contributes to editing efficiency, as there was strong conservation of four (conformation A) to five (conformation B) base pairs immediately upstream of the editing site (Fig. 2B). Disruption of this base pairing is clearly inhibitory to the reaction (Fig. 5B). The reselection results also indicate, though, that particular non-Watson-Crick pairs can also function upstream of the editing site (Fig. 6B). Although these results are in overall agreement with earlier mutagenesis, there are also some differences. Upstream base pairing was shown not to previously stimulate in vitro editing of a cytochrome $b$ mRNA transcript catalyzed by an $L$. tarentolae extract (Kabb et al. 2001). However, this mRNA is very inefficiently edited in vitro $(<1 \%$ of the molecules) and it is likely that other aspects of the cytochrome $b$ mRNA and gRNA transcripts are limiting the editing reaction. Although it was previously demonstrated that a 15-nt duplex 4 nt upstream of the editing site stimulated in vitro editing of a T. brucei ATPase mRNA transcript, placement of the duplex immediately adjacent to the editing site inhibited the editing reaction (Igo et al. 2002). As a result, it was concluded that having some single-stranded sequence immediately adjacent to the editing site is necessary for efficient editing. In contrast, our selection results clearly indicate that base pairing immediately adjacent to the editing site is not necessarily inhibitory. However, increasing the stability of the selected upstream helix partially inhibited the activity, indicating that some single-stranded character in the vicinity of the editing site facilitates optimal activity (Fig. 5C). Overall, it can be concluded that upstream base pairing can significantly stimulate the reaction, but editing can occur at a low level in its absence. Furthermore, some single-stranded RNA in the region upstream of the editing site, not necessarily immediately adjacent, can facilitate trypanosomatid editing, but it is not essential.

Aside from the base pairing and sequence constraints on the guiding nucleotides and the nucleotides immediately adjacent to the guiding nucleotides, there does not appear to be significant structural constraints on the gRNA. The weak hairpin loop structures that most natural gRNAs have the potential to form (Schmid et al. 1995, 1996) do not appear to be critical for the in vitro editing reaction. This is consistent with earlier mutagenesis (Cruz-Reyes and Sollner-Webb 1996). However, it is possible that there are regulatory elements on some natural gRNAs for which there would not have been pressure to select in vitro. Furthermore, as previously noted (Cruz-Reyes and Sollner-Webb 1996), the in vitro assays have been optimized for the editing of a single editing site, not an entire molecule as in nature. Presumably the editing of an entire mRNA would require additional interactions during editing, and as a result, additional gRNA structural elements could be required to support these interactions.

\section{Accuracy of the in vitro reaction}

The editing of an ND7 mRNA transcript within an L. tarentolae mitochondrial lysate is extremely inaccurate (Byrne et al. 1996; Kapushoc and Simpson 1999); an intense background ladder of larger products is formed during the reaction. Mostly on the basis of this observation, a model was proposed in which multiple Us are added to the $3^{\prime}$ hydroxyl of the $5^{\prime}$ cleavage product and then trimmed back by the editing machinery to the appropriate number (Alfonzo et 
al. 1997). However, the ladder of incorrect $U$ additions can be caused by several different mechanisms. First, an $\mathrm{A}+\mathrm{U}$ sequence element within the $5^{\prime}$ untranslated sequence of both the cytochrome $b$ and ND7 mRNAs is able to stimulate $\mathrm{U}$ insertions independent of gRNA (Brown et al. 1999) and deletion of this sequence has been shown to significantly reduce the background ladder of incorrect $U$ insertions within a cytochrome $b$ mRNA transcript (Oppegard et al. 2000). Second, the ND7 editing reaction was originally performed using a crude mitochondrial lysate (Byrne et al. 1996; Kapushoc and Simpson 1999). When a fractionated mitochondrial extract is used to catalyze ND7 mRNA editing, the ladder of larger insertion products is significantly diminished under our reaction conditions (Kabb et al. 2001). Third, it is clear from the reselection results that the nucleotides upstream of the editing site can also affect the editing accuracy (Fig. 6E), but inaccurate editing is not an intrinsic property of the reaction. For example, the insertion of more than the correct number of $U$ insertions is only rarely detected in the selected A-1 RNA (Figs. 3A, 7B). Furthermore, the in vitro $T$. brucei editing reaction is also extremely accurate (Igo et al. 2000). Although the proposed trimming model may possibly be occurring as a minor corrective mechanism, the evidence in support of it as the major reaction mechanism is not currently compelling.

\section{In vitro editing activity increases with increasing amounts of extract}

It has been difficult to obtain an editing assay that is linear with the quantity of added extract in both the direct $L$. tarentolae (Oppegard and Connell 2002) and T. brucei (Rusche et al. 1997; Panigrahi et al. 2001a) in vitro assays. As illustrated in Figure 7, the editing assay using the in vitro selected A-1 RNA is linear with extract concentration over the range from $3 \%$ to $40 \%$ correctly edited product. This is significant for two reasons. First it allows specific activity measurements to be made facilitating a more rigorous purification of the editing complex. Second, the result suggests that the previous difficulty in obtaining a linear assay results from there being an active conformation of the RNA substrate that is limiting the reaction. As a result, the major conformation of mRNA-gRNA duplexes studied in solution may not be the biologically significant conformation if the mRNAs are only edited to a minor extent in vitro.

\section{Conclusion}

The in vitro selection results, together with the previous mutagenesis and phylogenetic studies, define some of the critical RNA features that create sites of insertional trypanosomatid editing. Not all natural editing sites have all of the optimal features defined in vitro. For example, the first insertional editing site of $L$. tarentolae cytochrome $b$ mRNA is flanked by an upstream $\mathrm{C}$ and is very inefficiently edited in vitro (Oppegard et al. 2000), as would be predicted from both the mutagenesis and in vitro selection results. It is possible that RNA chaperones may facilitate the editing of these sites in vivo. Suboptimal sites make it possible to differentially regulate the editing of a specific mRNA, possibly through the regulation of a specific chaperone.

\section{MATERIALS AND METHODS}

\section{Materials}

The RNAs used in the editing assays were transcribed by T7 RNA polymerase from the corresponding oligodeoxynucleotides (Milligan and Uhlenbeck 1989). The transcription reactions and ligation conditions subsequently used to circularize the RNA editing substrates were performed as previously described (Oppegard and Connell 2002). Mitochondria were isolated from L. tarentolae UC strain, and the editing activity within a solubilized extract was sequentially fractionated over Q and SP-Sepharose columns (Oppegard and Connell 2002).

\section{The in vitro editing reaction}

The sequence flanking the random region of the RNA used for the initial selection (Fig. 1A) is mostly artificial. Nucleotides 19-27 correspond to the first $9 \mathrm{nt}$ of the cytochrome $b$ mRNA A $+\mathrm{U}$ element (nt 5371-5379 in LEIKPMAX; Brown et al. 1999), but the rationale for having this sequence in the RNA is not relevant to the selection of the gRNA-directed editing substrates described here.

Unless otherwise noted, 1 pmole of radiolabeled circular RNA was denatured at $65^{\circ} \mathrm{C}$ for $10 \mathrm{~min}$ in a $10-\mu \mathrm{L}$ volume containing 25 $\mathrm{mM}$ Tris $\left(\mathrm{pH} 8.3 ; 27^{\circ} \mathrm{C}\right)$ and $0.2 \mathrm{mM}$ EDTA. The RNA was added to $25 \mu \mathrm{L}$ editing buffer ( $40 \mathrm{mM}$ dithiothreitol, $40 \mathrm{mM} \mathrm{KCl}, 20 \mathrm{mM}$ $\mathrm{MgCl}_{2}, 6 \mathrm{mM}$ potassium phosphate, $2 \mathrm{mM}$ ATP, $2 \mathrm{mM}$ GTP, 2 $\mathrm{mM}$ UTP, $10 \mu \mathrm{g} / \mathrm{mL}$ leupeptin, $1 \mathrm{mg} / \mathrm{mL}$ Pefabloc SC) and then incubated for $10 \mathrm{~min}$ at room temperature. Mitochondrial extract $(15 \mu \mathrm{L})$ was added, and the reactions were incubated for $1 \mathrm{~h}$ at $27^{\circ} \mathrm{C}$. The reactions for the initial in vitro selection and characterization (Figs. 1B, 3A, and 5) were performed using approximately $10 \mu \mathrm{g}$ of the Q-Sepharose extract and the subsequent reselections and assays using $0.2-0.4 \mu \mathrm{g}$ of the SP-Sepharose editing fraction (Oppegard and Connell 2002). The reactions were terminated by the addition of EDTA to $20 \mathrm{mM}$, SDS to $0.5 \%$, and proteinase $\mathrm{K}$ treatment as previously described (Oppegard et al. 2000). After phenol-chloroform extraction and ethanol precipitation, the edited RNA was resolved on a 9\% polyacrylamide (acrylamide/bisacrylamide weight ratio of 19:1) $8 \mathrm{M}$ urea gel that was 60 $\mathrm{cm}$ long and $0.4 \mathrm{~mm}$ thick. The gel was run at $2400 \mathrm{~V}$ for approximately $2 \mathrm{~h}$ and quantified after PhosphorImager scanning (Molecular Dynamics).

\section{The in vitro selection}

The editing reaction for the initial cycle of selection contained 2 pmoles of the $23 \mathrm{~N}$ random RNA (Fig. 1A). Assuming no other biases, this would have resulted in a $99 \%$ probability of having representation of any combination of 19 contiguous nucleotides (Ciesiolka et al. 1996). The 9\% polyacrylamide gel used to resolve 
the editing products was exposed to X-ray film for $12 \mathrm{~h}$ at $-80^{\circ} \mathrm{C}$, and the region of the gel corresponding to one to three $\mathrm{U}$ insertions was excised for cDNA synthesis and subsequent PCR amplification (Fig. 1A); because significant edited product was not evident until the fourth cycle, radiolabeled synthetic markers were used to aid in excising the appropriate region of the gel. The PCR conditions were adjusted so that cDNA resulting from the reverse transcription of RNAs containing insertions within the fixed sequence could be amplified. The PCR was carried out in a $100 \mu \mathrm{L}$ volume and contained $1 \mathrm{mM}$ of each dNTP, $50 \mathrm{mM} \mathrm{KCl}, 5.1 \mathrm{mM}$ $\mathrm{MgCl}_{2}, 10 \mathrm{mM}$ Tris- $\mathrm{Cl}\left(\mathrm{pH} 9.0,25^{\circ} \mathrm{C}\right), 0.01 \%$ Triton $\mathrm{X}-100$, and $12 \mathrm{U}$ Taq DNA polymerase (Promega). The thermal cycler conditions consisted of one 3-min cycle at $94^{\circ} \mathrm{C}$ followed by five cycles of the following: $30 \mathrm{~s}$ at $94^{\circ} \mathrm{C}, 45 \mathrm{~s}$ at $45^{\circ} \mathrm{C}$, and $60 \mathrm{~s}$ at $65^{\circ} \mathrm{C}$. This was followed by another 35 cycles of $30 \mathrm{~s}$ at $94^{\circ} \mathrm{C}, 45 \mathrm{~s}$ at $50^{\circ} \mathrm{C}$, and $1 \mathrm{~min}$ at $72^{\circ} \mathrm{C}$; the $72^{\circ} \mathrm{C}$ extension time was increased by $3 \mathrm{~s}$ for each subsequent cycle.

After four rounds of selection, the edited circular RNA was cloned for sequencing. Several different RT-PCR primer pairs were used so that the location of the $\mathrm{U}$ insertions could be identified. The $\mathrm{U}$ insertions within the motif A RNAs were initially determined after RT-PCR with primers RP-2: TCTGAATTCAA CAAGAACAAGTTAAACGC, and FP-2: TAAGAATTCGGTT GCTTTATTTGTGGG. U insertions could only have been detected within a 10 -nt region immediately $5^{\prime}$ of the randomized region (Fig. 1A), as all other potential editing sites would be masked by the two RT-PCR primers. U insertions were detected at sites outside of this region in some of the selected RNAs by performing two parallel reverse transcription reactions using either RP-2, which binds to the fixed sequence downstream from the random region, or to RP-3: TCTGAATTCCCACAAATAAAGCAACC, which binds to the fixed sequence upstream of the editing sites. A poly(A) tail was added to both cDNA products using deoxynucleotidyltransferase (Roche), and the product amplified for cloning and sequencing using the appropriate reverse primer and FP-3: CTGGAATTCTTTTTTTTTTTTTTTTTT.

The primers used for the RT-PCR of the RNA from the two reselections were RP-4: TCTGAATTCAGAACAAGTTAAACGC CGC, and FP-4: TAAGAATTCTGTTGGTTGCTTTATTTG.

\section{Thin layer chromatography}

Editing of 1 pmole of unlabeled A-1 RNA containing one guiding nucleotide was done under the standard conditions already described except that $60 \mu \mathrm{Ci}$ of $\left[\alpha-{ }^{32} \mathrm{P}\right]$-UTP was included in the reaction and the total UTP concentration was reduced to $50 \mu \mathrm{M}$. After the reaction products were resolved by electrophoresis, the correctly edited circular RNA was identified by autoradiography, excised from the gel, eluted, and ethanol precipitated. The RNA was then resuspended in $2 \mu \mathrm{L}$ of $50 \mathrm{mM} \mathrm{NaOH}$ and incubated for $15 \mathrm{~min}$ at $98^{\circ} \mathrm{C}$ in a thermal cycler with a heated lid. Formic acid was added to $50 \mathrm{mM}$ and the reaction products spotted on a poly(ethylenimine) cellulose TLC plate containing a fluorescent indicator (Selecto Scientific); the plate had been predeveloped with distilled $\mathrm{H}_{2} \mathrm{O}$ and dried. Unlabeled 3' AMP and 3' UMP standards $(1 \mu \mathrm{g})$ were also spotted on the plate. The TLC plate was developed for $10 \mathrm{~cm}$ using $1 \mathrm{M}$ formic acid as the solvent (Zweig and Sherma 1972). The unlabeled standards were visualized under UV light and the radiolabeled monophosphate hydrolysis products visualized after PhosphorImager scanning.

\section{Chemical modifications}

The chemical modifications were performed as previously described (Krol and Carbon 1989) with the exception that the CMCT concentration in the reactions was reduced to $2.6 \mu \mathrm{g} / \mu \mathrm{L}$ and the $\mathrm{CMCT}$ denaturing reaction performed at $70^{\circ} \mathrm{C}$ for $50 \mathrm{~s}$. The reverse primer shown in Figure 1A was used for the RT reactions.

\section{ACKNOWLEDGMENTS}

We thank Matthew Hillestad for technical assistance. This work was supported by the American Heart Association and by National Institutes of Health Grant AI 41138

The publication costs of this article were defrayed in part by payment of page charges. This article must therefore be hereby marked "advertisement" in accordance with 18 USC section 1734 solely to indicate this fact.

Received November 6, 2002; accepted January 8, 2003.

\section{REFERENCES}

Alfonzo, J.D., Thiemann, O., and Simpson L. 1997. The mechanism of $\mathrm{U}$ insertion/deletion RNA editing in kinetoplastid mitochondria. Nucleic Acids Res 25: 3751-3759.

Aphasizhev, R., Sbicego, S., Peris, M., Jang, S.H., Aphasizheva, I., Simpson, A.M., Rivlin, A., and Simpson, L. 2002. Trypanosome mitochondrial 3' terminal uridylyl transferase (TUTase): The key enzyme in U insertion/deletion RNA editing. Cell 108: 637-648.

Benne, R. 1992. RNA editing in trypanosomes. The us(e) of guide RNAs. Mol. Biol. Rep. 16: 217-227.

Benne, R., Van den Burg, J., Brakenhoff, J.P., Sloof, P., Van Boom, J.H., and Tromp, M.C. 1986. Major transcript of the frameshifted coxII gene from trypanosome mitochondria contains four nucleotides that are not encoded in the DNA. Cell 46: 819-826.

Blum, B., Bakalara, N., and Simpson, L. 1990. A model for RNA editing in kinetoplastid mitochondria: "Guide" RNA molecules transcribed from maxicircle DNA provide the edited information. Cell 60: 189-198.

Brown, L.M., Burbach, B.J., McKenzie, B.A., and Connell, G.J. 1999. A cis-acting A-U sequence element induces kinetoplastid U-insertions. J. Biol. Chem. 274: 6295-6304.

Burgess, M.L.K. and Stuart, K. 2000. Sequence bias in edited kinetoplastid RNAs. RNA 6: 1492-1497.

Byrne, E.M., Connell, G.J., and Simpson, L. 1996. Guide RNA-directed uridine insertion RNA editing in vitro. EMBO J. 15: 6758-6765.

Ciesiolka, J., Illangasekare, M., Majerfeld, I., Nickles, T., Welch, M., Yarus, M., and Zinnen, S. 1996. Affinity selection-amplification from randomized ribooligonucleotide pools. Methods Enzymol. 267: 315-335.

Connell, G.J., Byrne, E., and Simpson, L. 1997. Guide RNA-independent and guide RNA-dependent uridine-insertion into cytochrome $b$ mRNA in a mitochondrial lysate from Leishmania tarentolae. J. Biol. Chem. 272: 4212-4218.

Corell, R.A., Read, L.K., Riley, G.R., Nellissery, J.K., Allen, T.E., Kable, M.L., Wachal, M.D., Seiwert, S.D., Myler, P.J., and Stuart, K.D. 1996. Complexes from Trypanosoma brucei that exhibit deletion editing and other editing-associated properties. Mol. Cell. Biol. 16: $1410-1418$

Cruz-Reyes, J. and Sollner-Webb, B. 1996. Trypanosome U-deletional RNA editing involves guide RNA-directed endonuclease cleavage, terminal U exonuclease, and RNA ligase activities. Proc. Natl. Acad. Sci. 93: 8901-8906.

Cruz-Reyes, J., Rusche, L.N., Piller, K.J., and Sollner-Webb, B. 1998. T. brucei RNA editing: Adenosine nucleotides inversely affect U-de- 
letion and U-insertion reactions at mRNA cleavage. Mol. Cell 1: 401-409.

Cruz-Reyes, J., Zhelonkina, A., Rusche, L., and Sollner-Webb, B. 2001. Trypanosome RNA editing: Simple guide RNA features enhance U deletion 100-fold. Mol. Cell. Biol. 21: 884-892.

Drozdz, M., Palazzo, S.S., Salavati, R., O'Rear, J., ,Clayton, C., and Stuart, K. 2002. TbMP81 is required for RNA editing in Trypanosoma brucei. EMBO J. 21: 1791-1799.

Ellington, A.D. and Szostak, J.W. 1990. In vitro selection of RNA molecules that bind specific ligands. Nature 346: 818-822.

Estevez, A.M. and Simpson, L. 1999. Uridine insertion/deletion RNA editing in trypanosome mitochondria: A review. Gene 240: 247260.

Freier, S.M., Kierzek, R., Jaeger, J.A., Sugimoto, N., Caruthers, M.H., Neilson, T., and Turner, D.H. 1986. Improved free-energy parameters for predictions of RNA duplex stability. Proc. Natl. Acad. Sci. 83: 9373-9377.

Huang, C.E., O’Hearn, S.F., and Sollner-Webb, B. 2002. Assembly and function of the RNA editing complex in Trypanosoma brucei requires band III protein. Mol. Cell. Biol. 22: 3194-3203.

Igo, R.P., Palazzo, S.S., Burgess, M.L.K., Panigrahi, A.K., and Stuart, K. 2000. Uridylate addition and RNA ligation contribute to the specificity of kinetoplastid insertion RNA editing. Mol. Cell. Biol. 20: 8447-8457.

Igo, R.P., Lawson, S.D., and Stuart, K. 2002. RNA sequence and base pairing effects on insertion editing in Trypanosoma brucei. Mol. Cell. Biol. 22: 1567-1576.

Kabb, A.L., Oppegard, L.M., McKenzie, B.A., and Connell, G.J. 2001. A mRNA determinant of gRNA-directed kinetoplastid editing. Nucleic Acids Res. 29: 2575-2580.

Kable, M.L., Seiwert, S.D., Heidmann, S., and Stuart, K. 1996. RNA editing: A mechanism for gRNA-specified uridylate insertion into precursor mRNA. Science 273: 1189-1195.

Kapushoc, S.T. and Simpson, L. 1999. In vitro uridine insertion RNA editing mediated by cis-acting guide RNAs. RNA 5: 656-669.

Krol, A. and Carbon, P. 1989. A guide for probing native small nuclear RNA and ribonucleoprotein structures. Methods Enzymol. 180: 212-227.

Madison-Antenucci, S., Grams, J., and Hajduk, S.L. 2002. Editing machines: The complexities of trypanosome RNA editing. Cell 108: $435-438$

Maslov, D.A. and Simpson, L. 1992. The polarity of editing within a multiple gRNA-mediated domain is due to formation of anchors for upstream gRNAs by downstream editing. Cell 70: 459-467.

McManus, M.T., Shimamura, M., Grams, J., and Hajduk, S.L. 2001. Identification of candidate mitochondrial RNA editing ligases from Trypanosoma brucei. RNA 7: 167-175.

Milligan, J.F. and Uhlenbeck, O.C. 1989. Synthesis of small RNAs using T7 RNA polymerase. Methods Enzymol. 180: 51-62.
Oppegard, L.M. and Connell, G.J. 2002. Direct visualization of RNA editing within a Leishmania mitochondrial extract. Int. J. Parasitol. 32: 859-866.

Oppegard, L.M., Kabb, A.L., and Connell, G.J. 2000. Activation of guide RNA-directed editing of a cytochrome $b$ mRNA. J. Biol. Chem. 275: 33911-33919.

Panigrahi, A.K., Gygi, S.P., Ernst, N.L., Igo, R.P., Palazzo, S.S., Schnaufer, A., Weston, D.S., Carmean, N., Salavati, R., Aebersold, R., et al. 2001a. Association of two novel proteins, TbMP52 and TbMP48, with the Trypanosoma brucei RNA editing complex. Mol. Cell. Biol. 21: 380-389.

Panigrahi, A.K., Schnaufer, A., Carmean, N., Igo, R.P., Gygi, S.P., Ernst, N.L., Palazzo, S.S., Weston, D.S., Abersold, R., Salavati, R., et al. 2001b. Four related proteins of the Trypanosoma brucei RNA editing complex. Mol. Cell. Biol. 21: 6833-6840.

Pollard, V.W., Harris, M.E., and Hajduk, S.L. 1992. Native mRNA editing complexes from Trypanosoma brucei mitochondria. EMBO J. 11: 4429-4438.

Rusche, L.N., Cruz-Reyes, J., Piller, K.J., and Sollner-Webb, B. 1997. Purification of a functional enzymatic editing complex from Trypanosoma brucei mitochondria. EMBO J. 16: 4069-4081.

Rusche, L.N., Huang, C.E., Piller, K.J., Hemann, M., Wirtz, E., and Sollner-Webb, B. 2001. The two RNA ligases of the Trypanosoma brucei RNA editing complex: Cloning the essential band IV gene and identifying the band V gene. Mol. Cell. Biol. 21: 979-989.

Schmid, B., Riley, G.R., Stuart, K., and Goringer, H.U. 1995. The secondary structure of guide RNA molecules from Trypanosoma brucei. Nucleic Acids Res. 23: 3093-3102.

Schmid, B., Read, L.K., Stuart, K., and Goringer, H.U. 1996. Experimental verification of the secondary structures of guide RNA-premRNA chimaeric molecules in Trypanosoma brucei. Eur. J. Biochem. 240: 721-731.

Schnaufer, A., Panigrahi, A.K., Panicucci, B., Igo, R.P., Wirtz, E., Salavati, R., Stuart K. 2001. An RNA ligase essential for RNA editing and survival of the bloodstream form of Trypanosoma brucei. Science 291: 2159-2162.

Seiwert, S.D., Heidmann, S., and Stuart, K. 1996. Direct visualization of uridylate deletion in vitro suggests a mechanism for kinetoplastid RNA editing. Cell 84: 831-841.

Stuart, K. and Panigrahi, A.K. 2002. RNA editing: Complexity and complications. Mol. Microbiol. 45: 591-596.

Thiemann, O.H., Maslov, D.A., and Simpson, L. 1994. Disruption of RNA editing in Leishmania tarentolae by the loss of minicircleencoded guide RNA genes. EMBO J. 13: 5689-5700.

Tuerk, C. and Gold, L. 1990. Systematic evolution of ligands by exponential enrichment: RNA ligands to bacteriophage T4 DNA polymerase. Science 249: 505-510.

Zweig, G. and Sherma, J. 1972. CRC handbook of chromatography. CRC Press, Cleveland, $\mathrm{OH}$. 

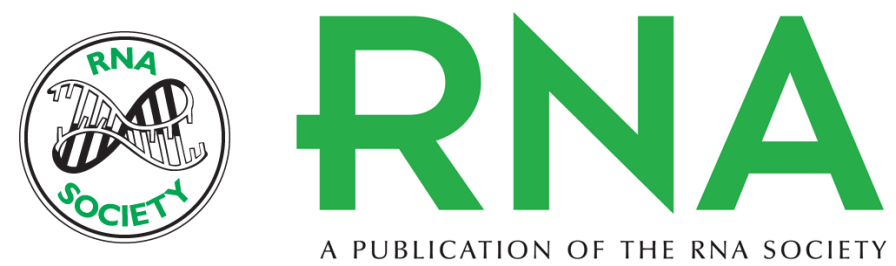

\section{Sequence and structural requirements for optimal guide RNA-directed insertional editing within Leishmania tarentolae}

RAJ D. PAI, LISA M. OPPEGARD and GREGORY J. CONNELL

RNA 2003 9: 469-483

References This article cites 43 articles, 21 of which can be accessed free at: http://rnajournal.cshlp.org/content/9/4/469.full.html\#ref-list-1

\section{License}

Email Alerting Receive free email alerts when new articles cite this article - sign up in the box at the Service top right corner of the article or click here. 